\title{
KAJIAN LOCAL GENIUS ARSITEKTUR KAMPUNG NAGA TERHADAP SUSTAINABLE ARCHITECTURE
}

\author{
Taufiq Rizza Nuzuluddin ${ }^{1}$, Tri Susetyo Andadari ${ }^{1}$ \\ ${ }^{1}$ Universitas Pandanaran \\ Jalan Banjarsari Barat No 1 Pedalangan, Banyumanik Semarang \\ Email: taufiqrizza@unpand.ac.id
}

\begin{abstract}
ABSTRAK
Indonesia memiliki banyak arsitektur tradisional yang sampai saat ini keberadaannya masih bertahan di tengah gempuran arus teknologi. Bertahannya arsitektur tradisional tersebut karena kesadaran masyarakat setempat untuk tetap memelihara ke-local genius-an yang terkandung pada masing-masing arsitektur tradisional tersebut. Disisi lain, arsitektur tradisional selau dikaitkan dengan kesederhananaan, penyatuan dengan alam dan keramahan lingkungan yang dalam istilah ilmiahnya disebut sustainable architecture. Kampung Naga yang terletak di wilayah Desa Neglasari, Kecamatan Salawu, Kabupaten Tasikmalaya, Jawa Barat memiliki local genius. Penelitian ini bertujuan untuk mengkaji lebih dalam hubungan keterkaitan ke-local genius-an dengan sustainable architecture pada perkampungan Kampung Naga. Metode penelitian yang digunakan yaitu metode kualitatif deskriptif dengan data yang didapatkan dari observasi langsung pada perkampungan Kampung Naga, wawancara dengan beberapa responden penghuni perkambungan Kampung Naga dan studi literatur terkait local genius dan sustainable architecture. Hasil kajian akhir menunjukkan adanya hubungan yang selaras antara local genius dan sustainable architecture pada perkampungan Kampung Naga.Hidup selaras dengan alam adalah cara bertahan masyarakat Kampung Naga terhadap permasalahan yang ada. Kesederhanaan, kebersamaan dan menghormati leluhur, sebagai local genius masyarakat Kampung Naga, dijadikan sebagai dasar dan landasan dalam bermasyarakat, baik dalam hubungan antar manusia, manusia dengan alam, maupun manusia dengan Sang Penciptanya.
\end{abstract}

Keyword : Local genius, Kampung Naga, Sustainabe architecture

\section{PENDAHULUAN}

Salah satu arsitektur tradisional yang masih bertahan dengan norma-norma lokal dan bisa kita jumpai saat ini adalah perkampungan Kampung Naga. Bukan hanya tentang arsitekturnya tetapi tentang tata kelola masyarakat dan socio-culture-nya, menarik untuk digali ditengah maraknya teknologi, globalisasi dan individualisme yang tumbuh berkembang saat ini. Selain peran serta masyarakat setempat dalam menjaga local genius yang dimiliki, peran pemerintah dalam menjaga dan melindungi keberlanjutan perkampungan Kampung Naga ini menjadi faktor utama tetap berlangsungnya kehidupan tradisional di perkampungan Kampung Naga. Untuk itu, penelitian ini berusaha mendapatkan pola hubungan keterkaitan antara local genius pada perkampungan sustainable architecture yang terdapat pada Kampung Naga yang tentunya akan menambah wawasan masyarakat untuk lebih terbuka terhadap arsitektur tradisional.

\section{Local Wisdom (Kearifan Lokal)}

Secara etimologis, kearifan (wisdom) berarti kemampuan seseorang dalam menggunakan akal pikirannya untuk menyikapi sesuatu kejadian, obyek atau situasi. Sedangkan lokal, menunjukkan ruang interaksi di mana peristiwa atau situasi tersebut terjadi. Dengan demikian, kearifan lokal secara substansial merupakan nilai dan norma yang berlaku dalam suatu masyarakat yang diyakini kebenarannya dan menjadi acuan dalam bertindak dan berperilaku sehari-hari (kearifan lokal sebagai aset budaya bangsa, www.academia.edu).

Sedangkan menurut Kamus Inggris Indonesia karya John M. Echols dan Hassan Syadily, local berarti setempat sedangkan wisdom (kearifan) berarti kebijaksanaan. Secara umum maka local wisdom (kearifan lokal) adalah gagasan-gagasan 
setempat (local) yang bersifat bijaksana, penuh kearifan, bernilai baik, yang tertanam dan diikuti oleh anggota masyarakatnya. Dalam disiplin antropologi, kondisi seperti ini dikenal dengan istilah local genius. Dalam bukunya Kepribadian Budaya Bangsa (Local Genius), Ayatrohaedi (1986) mengatakan bahwa unsur budaya daerah potensial sebagai local genius karena telah teruji kemampuannya untuk bertahan sampai sekarang.

\section{Sustainable Architecture}

Sustainable Architecture (Arsitektur Berkelanjutan) adalah sebuah konsep yang mendukung keberlanjutan lingkungan, yaitu konsep mempertahankan sumber daya alam agar bertahan lebih lama yang dikaitkan dengan umur potensi vital sumber daya alam dan lingkungan ekologis manusia, seperti sistem iklim planet, sistem pertanian, industri, kehutanan dan tentu saja arsitektur. Ada dua tujuan utama Sustainable architecture, yaitu :

- Bangunan berkelanjutan harus meminimalisir dampak terhadap lingkungan

- Bangunan harus mampu memberi kontribusi yang positif pada lingkungan social didalamnya, dengan mengatasi kebutuhan masyarakat dan meningkatkan kualitas lingkungan.

Paola Sassi (2006) melalui teori for sustainable architecture-nya, memberikan beberapa strategi untuk mencapai suatu kondisi sustainable yaitu : natural landscapping, site preservation, visual amenity, economic and social well-being, day lighting and natural ventilation, water management, reduce, reuse, recycle and renewable material dan embodied energy and energy efficiency.

1. Natural Landscaping

Bangunan didirikan dengan meminimalisir intervensi terhadap lingkungansehingga kondisi alami lingkungan tetap terjaga dan terjadi interaksi antara bangunan dantapaknya. Adanya perubahan yang terjadidari lingkungan alamiah (asal-mulanya) menjadi lingkungan buatan (hasil akhirnya), maka perubahan-perubahan yang semestinya dapat diprediksi dapat ditanggulangi secara teknis. Kondisi air, iklim, topografi, tanah, udara, serta tumbuhan menjadi perhatian utama dalam menciptakan sustainable architecture sehingga bangunan akan memiliki respon yang tepatterhadap site (respect for site).

2. Site Preservation

Terdapat beberapa strategi yang dilakukan dalam upaya pelestarian lingkungan yaitu:

- Botanical Garden, sebagai upaya pelestarian keragaman hayati yang ada.

- Biology Pond, sebagai tempat pengolahan air limbah bangunan secara biologis dan tempat hidup untuk tanaman air.

- Green Roof, menjaga keanekaragaman hayati serta strategi untuk menjaga iklim mikro agar tetap terjaga.

- Native Plantings, penanaman tumbuhan baru untuk menciptakan lingkungan alami.

3. Visual Amenity

Visual Amenity dalam hal ini berkaitan dengan zonasi, orientasi, serta skala. Bangunan harus memiliki ketepatan zonasi. Pembagian ruang public dan ruang privatharus jelas. Orientasi bangunan berkaitan iklim setempat, artinya setiap orientasi selalu dihadapkan pada akibatakibat yang akan timbul yang berkaitan dengan iklim. Arah hadap bangunan sebaiknya adalah utara selatan. Bangunan harus memiliki kesesuaian skala dengan standar visual penghuni. Sehingga visual yang tebentuk akan memiliki standar kenyaman yang baik. Ruang, sirkulasi dan pemilihan detail-detail bangunan yang tepat akan menciptakan visual amenity spacesyang baik.

4. Economic and Social Well-being

Dalam perspektif sosial keberlanjutan adalah potensi masyarakat untuk memelihara kesejahteraan jangka panjang. Kesejahteraan yang dimaksud memiliki perspektif, lingkungan, ekonomi dan sosial. Memenuhi kebutuhan sekarang tanpamengorbankan pemenuhan kebutuhan generasi masa depan. Salah satu faktor yang harus dihadapi untuk mencapai pembangunan berkelanjutan adalah bagaimana memperbaiki kehancuran lingkungan tanpa mengorbankan kebutuhan pembangunan ekonomi dan keadilan sosial. Tujuan pengelolaan lingkungan adalah pemanfaatan dan konservasi untuk kesejahteraan masyarakat dalam hal ini terdapat dua kriteria utama yaitu, Economically profitable, dan Socially acceptable. 
5. Daylighting and Natural Ventilation

Tujuan perlunya 2 elemen ini agar ruangruang di dalam bangunan mendapat pencahayaan dan penghawaan alami cukup, sehingga memberi kenyamanan pemakai dalam melakukan aktivitasnya. Ruang-ruang yang memiliki penghawaan dan pencahayaan alami baik juga akan memiliki kelembaban udara cukup sehingga kesehatan lingkungan tetap terjaga. Selain itu, memiliki penghawaan dan pencahayaan alami yang cukup berarti menghemat energi listrik yang diperlukan.

6. Water Management

Sistem pengelolaan air terbagi menjadi tiga yaitu sIstem air bersih, sistem air kotor, dan sistem air kotor padat. Banyaknya kebutuhan air yang akan digunakan dalam pengelolaan bangunan mendorong perlunya langkah penghematan agar tidak terjadi kelangkaan serta tidak menyebabkan kerusakan lingkungan antara lain dengan penggunaan kembali air limbah (reuse) dan rainwater harvesting.

7. Reduce, Reuse, Recycle \& Renewable Material

Suatu bangunan seharusnya dirancang mengoptimalkan material yang adadengan meminimalkan penggunaan material baru, dimana pada akhir umur bangunandapat digunakan kembali unutk membentuk tatanan arsitektur lainnya (Limitting New Resources). Penggunaan material terbarukan dapat dilakukan dengan pemanfaatan material lokal yang banyak ditemui di sekitar site.

8. Embodied Energy and Energy Efficiency

Bangunan tidak menggunakan energy terbarukan seperti panel surya, vortex, dll, namun banyak memanfaatkan low technology. Hal ini bertujuan untuk menghemat waktu pengerjaan juga terkait dengan cost.Sistem yang memungkinkan adalahmenyeimbangkan suhu dan memaksimalkan cahaya yang masuk ke dalam bangunan (Working with Climate). Seminimal mungkin menggunakan sumber energi yang langka atau membutuhkan waktu yang lama untuk menghasilkannya kembali (minimize energyscarcity). Bangunan harus mampu memodifikasi iklim dan dibuat beradaptasi dengan lingkungan bukan merubahlingkungan yang sudah ada.

\section{METODOLOGI}

Penelitian ini berusaha memecahkan permasalahan dengan paradigma kualitatif, dengan cara berfikir induktif, dengan tipologi pendekatan adalah rasionalistik kualitatif. Pengambilan data didasarkan pada studi literatur mengenai local genius dan sustainable architecture, observasi dan wawancara langsung dengan penghuni perkampungan Kampung Naga.

\section{HASIL DAN PEMBAHASAN}

\section{Letak Geografis Kampung Naga}

Secara administratif Kampung Naga berada di wilayah Desa Neglasari, Kecamatan Salawu, Kabupaten Tasikmalaya, Propinsi Jawa Barat. Lokasi Kampung Naga tidak jauh dari jalan raya yang menghubungkan kota Garut dengan Kota Tasikmalaya. Adapun batas wilayahnya di sebelah Barat adalah hutan keramat, di sebelah Selatan sawah penduduk, di sebelah Utara dan Timur dibatasi oleh sungai Ciwulan yang sumber airnya berasal dari Gunung Cikuray Garut. Gambaran umum Kampung Naga bisa dilihat pada gambar 1. Jarak dari Kota Tasikmalaya ke Kampung Naga sekitar $30 \mathrm{Km}$, sedangkan dari Kota Garut jaraknya $26 \mathrm{Km}$.

Keunikan yang pertama didapat saat mengunjungi Kampung Naga adalah perjalanan menuju lokasi yang harus menuruni tangga yang sudah di plaster (Sunda Sengked) sampai ketepi sungai Ciwulan dengan kemiringan sekitar 45 derajat dengan jarak kira-kira 500 meter dan dilanjutkan dengan jalan setapak menyusuri sungai Ciwulan sampai kedalam Kampung Naga. Letak dan batas wilayah kampung naga bisa dilihat pada gambar 2 .

Secara letak geografis dan keberadaan Kampung Naga, terdapat local genius yang sampai sekarang masih bisa dilihat keberadaannya yaitu pemilihan lokasi pemukiman Kampung naga yang tidak berpindah, tidak bertambah dan tidak berkurang. Oleh penduduk setempat ini dianggap sebagai norma yang harus terus dijaga hingga saat ini. Untuk menjaga besaran lokasi perkampungan terkait pertambahan penduduk, di atasi dengan keluarnya anggota keluarga yang muda dari perkampungan Kampung Naga keluar Kampung Naga. Namun dalam upacara adat, penduduk luar Kampung Naga masih dilibatkan. 


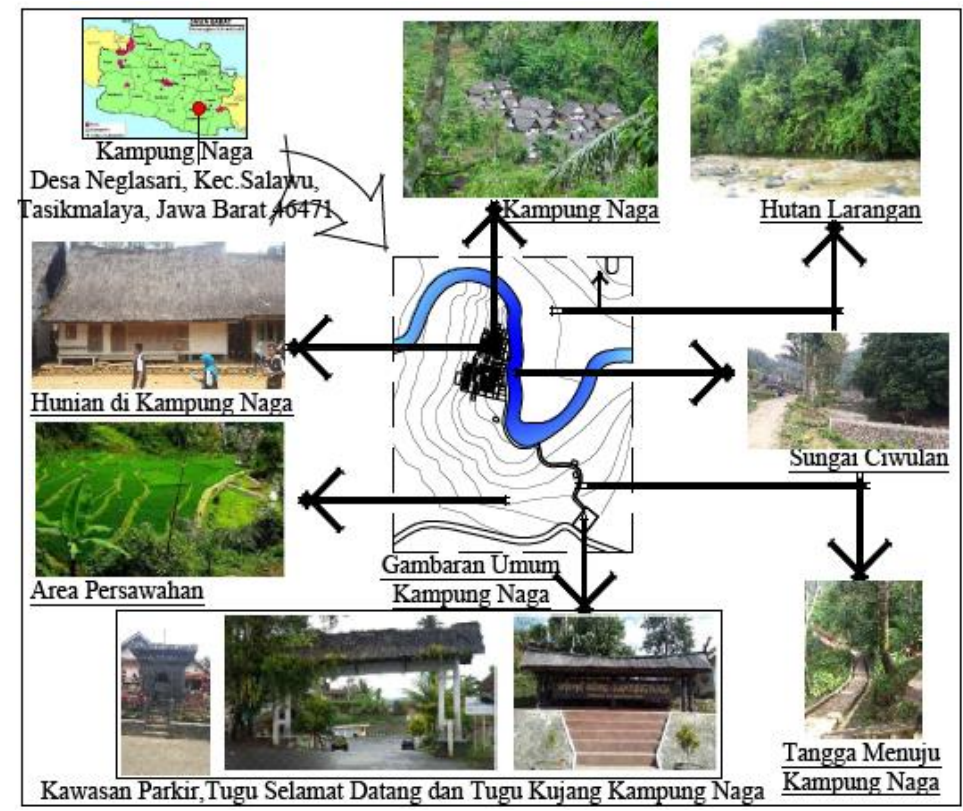

Gambar 1. Kampung Naga

Sumber : Dokumentasi dan Analisis Pribadi, 2015

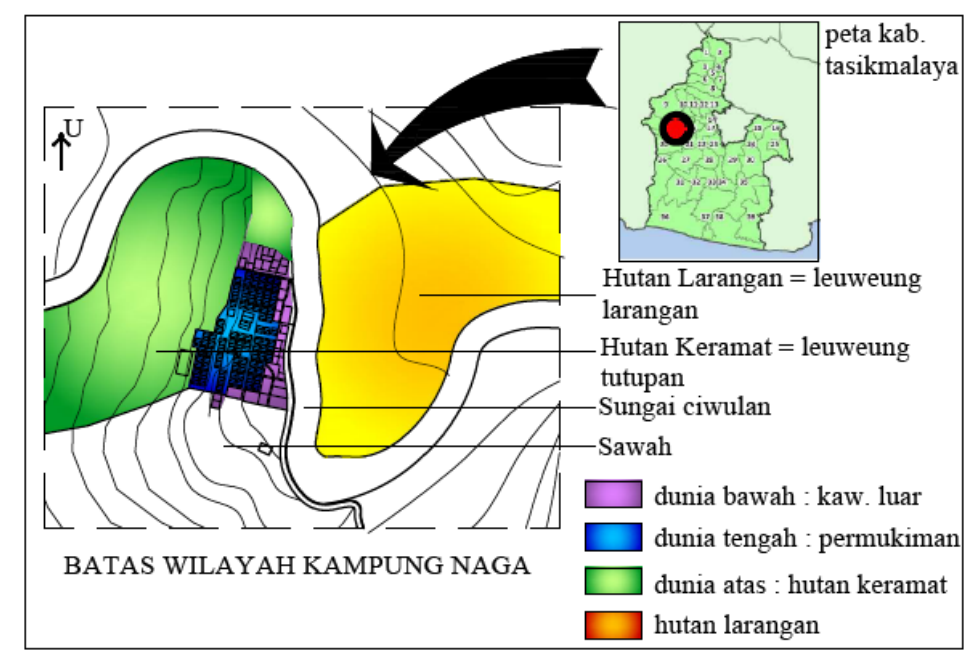

Gambar 2. Batas Kampung Naga

Sumber : Analisis pribadi, 2015

Dari sisi sustainable architecture letak Kampung Naga yang tetap, tidak berubah, tidak bertambah dan tidak berkurang adalah selaras dengan kaidah sustaianable yang dikemukakan oleh Paola Sassi, yaitu natural landsacpping, dimana lingkungan buatan, dalam hal ini perkampungan Kampung Naga, dibangun dengan meminimalisisr dampak terhadap lingkungan alamiah, termasuk tidak menambah luasan perkampungan.

\section{Karakteristik Kampung Naga}

Hasil observasi lokasi dan wawancara terhadap responden didapat beberapa karakteristik Kampung Naga terkait dengan local genius dan sustainable architecture, yaitu:

- Terletak di dataran tinggi, dengan kontur berbukit di lereng barat daya Gunung Galunggung. Luas area perkampungan 4 ha dan luas permukiman 1,5 ha.

Terkait dengan kosmologi yang diyakini penduduk setempat, pemilihan perkampungan pada daerah perbukitan, merupakan local genius yang diyakini kebenarannya oleh masyarakat setempat karena, perkampungan dianggap berada dalam dunia tengah, diantara dunia atas dan dunia bawah. 
Sedangkan dari sisi sustainable architecture, pemilihan perkampungan dengan kontur berbukit tanpa merubah tipologi tanah, merupakan salah satu kaidah natural landscapping dalam sustainable architecture oleh Paola Sassi.

- Jumlah penduduk Kampung Naga adalah 314 orang dengan 109 Kepala Keluarga (KK).

Mempertahankan jumlah penghuni perkampungan Kampung Naga yang tidak berubah secara signifikan dengan pemilihan penduduk yang berhak menghuni Kampung Naga, berdasarkan keturunan, merupakan salah satu local genius masyarakat setempat, sebagai upaya untuk mempertahankan keaslian warga dari kontaminasi luar, menjaga keseimbangan dengan alam sekitar, mengurangi dampak buruknya terhadap kelestarian lingkungan. Kestabilan jumlah penghuni ini, sesuai dengan kaidah sustainable architecture oleh Paola Sassi tentang visual amenity, dimana pengaturan skala ruang disesuaikan dengan standard visual penghuni, dalam hal ini termasuk banyaknya penghuni dalam karya arsitektur.

Agama yang dianut mayoritas adalah Islam, namun ada beberapa kaidah Islam yang dikolaborasikan dengan adat istiadat setempat, seperti upacara hajat sasih.

Upacara adat ini, jelas merupakan salah satu local genius yang bernilai tinggi, dimana tata urutan dan pelaksana upacara adat sarat dengan simbol-simbol pendekatan diri kepada Yang Maha Pencipta. Tentunya ini sama sekali tidak terkait dengan sustainable.

- Mata pencaharian pokok masyarakat Kampung Naga adalah petani dan membuat barang-barang kerajinan tangan sebagai pekerjaan sambilan.

Dengan bekerja sebagai petani, mereka beranggapan bahwa selain menghormati leluhur, juga menjaga alam dri kerusakan akibat perubahan tata guna lahan. Tentu saja ini merupakan bagian dari local genius yang masih dipegang teguh sebagian besar penghuni Kampung Naga. Dan merupakan bagian dari sustainable architecture terutama dalam hal site preservation, yaitu penanaman kembali lahan produktif dan adaptasi lingkungan.

- Rata-rata tingkat pendidikan penduduk Kampung Naga hanya sampai Sekolah Dasar. Hal itu disebabkan oleh keterbatasan biaya, pola pemikiran masyarakat setempat yang menganggap kurang pentingnya pendidikan tinggi dan perlunya mencari pengetahuan berdasarkan pengalaman dan alam.

Pola pikir untuk hanya menyatu dan mencari pengetahuan dari alam ini, dianggap sebagai satu local genius, melebihi tekhnologi. Walaupun mereka bisa survive, namun perlu perhatian khusus, bukan hanya dari pemerintah, namun pihak terkait, supaya tetap tercapai keadilan sosial bagi masyarakat setempat tanap merusak local genius yang ada.

- Sistem kepemimpinan pada Kampung Naga ada 2 macam yaitu pemerintahan desa (berhubungan dengan pemerintahan) dan pemimpin adat atau Kuncen (berhubungan dengan adat istiadat). Dimana keduanya saling menghormati wewenang dan tanggung jawab masing-masing.

Penghormatan terhadap pemimpin, baik pemimpin adat maupun pemimpin pemerintahan, termasuk bagian dari norma dan tata krama terhadap orang tua dan leluhur yang terus dijunjung oleh penghuni Kampung Naga.

- Masyarakat Kampung Naga memiliki aturan hukum sendiri yang tak tertulis.

Aturan tidak tertulis itu berupa larangan, wasiat dan akibat. Artinya siapa saja yang melanggar larangan/pamali/tabu (ketentuan hukum yang tidak tertulis yang dibuat oleh nenek moyang yang tidak dapat dilanggar dan harus dijunjung tinggi oleh setiap orang), tidak mendapatkan sanksi yang jelas, tetapi akan menerima akibatnya sendiri. Aturan tidak tertulis itu misalnya dalam tata cara membangun dan bentuk rumah, letak, arah rumah, pakaian upacara, kesenian, dan sebagainya. Jelas ini merupakan salah satu local genius masyarakat setempat yang terus dipegang teguh.

- Keinginan untuk menyatu dengan alam, tidak merusak alam dan beradaptasi dengan alam.

Ini menjadikan masyarakat Kampung Naga hanya menggunakan peralatan-peralatan sederhana tanpa teknologi, seperti cangkul dibandingkan dengan tarktor, bahan bakar kayu dibandingkan dengan kompor gas, lampu minyak tanah dibandingkan dengan listrik, bahan bambu dibandingkan dinding bata dll. Konsep ini sangat sesuai dengan 
konsep embodied energy and energy efficieny dalam sustainable architecture, dimana terdapat upaya penggunaan alat low technology, dengan waktu pengerjaan yang singkat.

\section{Pola Perkampungan dan Bentuk Bangunan}

Pola perkampungan pada masyarakat Kampung Naga, merupakan local genius yang masih terus dipertahankan oleh masyarakat setempat. Hal ini mengandung filosofi bahwa masyarakat Kampung Naga menjaga keseimbangan dan harmonisasi kehidupan manusia dengan alam. Adanya kerusakan alam akan berpengaruh terhadap kelangsungan kehidupan masyarakat itu sendiri.

Pola perkampungan pada Kampung Naga, sesuai dengan kosmografi dibagi dalam 3 wilayah, yaitu:

- Kawasan Luar :

menggambarkan dunia bawah, disini terdapat bangunan : sawah, kolam kebun, saung lisung

- Kawasan permukiman :

menggambarkan dunia tengah, disini terdapat bangunan rumah, bale patemon, masjid, bumi ageng

- Hutan Keramat :

menggambarkan dunia atas, disini terdapat makam leluhur, termasuk makam eyang Singaparana.

Sebagai local genius, ini membuktikan bahwa masyarakat Kampung Naga, secara hakiki mengakui keberadaan Tuhan dan senantiasa menghormati leluhur dimana pembagian zonasi ini menunjukkan tingkat kesucian dan tingkat kedekatan terhadap Penciptanya. Pola zonasi Kampung Naga berdasarkan kosmografi bisa dilihat pada gambar 3 .

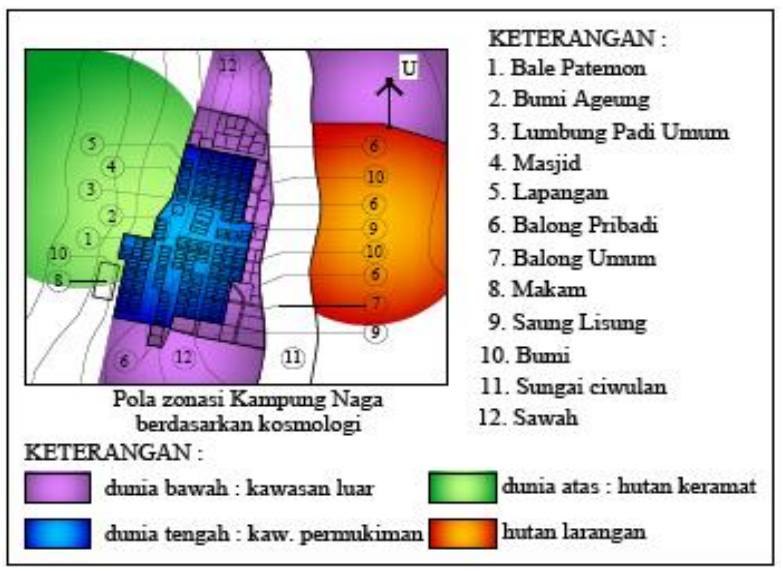

Gambar 3. Zonasi Kampung Naga Sumber : analisa pribadi, 2015
Pola pemukiman yang mengikuti garis kontur lahan, selaras dengan kaidah kosmologi, dimana untuk yang dunia bawah (kawasan luar) posisinya berada di sisi bagian bawah terhadap kontur, dunia tengah (kawasan permukiman) posisinya berada di sisi bagian tengah terhadap kontur, dan dunia atas (makam) posisinya berada di sisi bagian paling atas terhadap kontur.

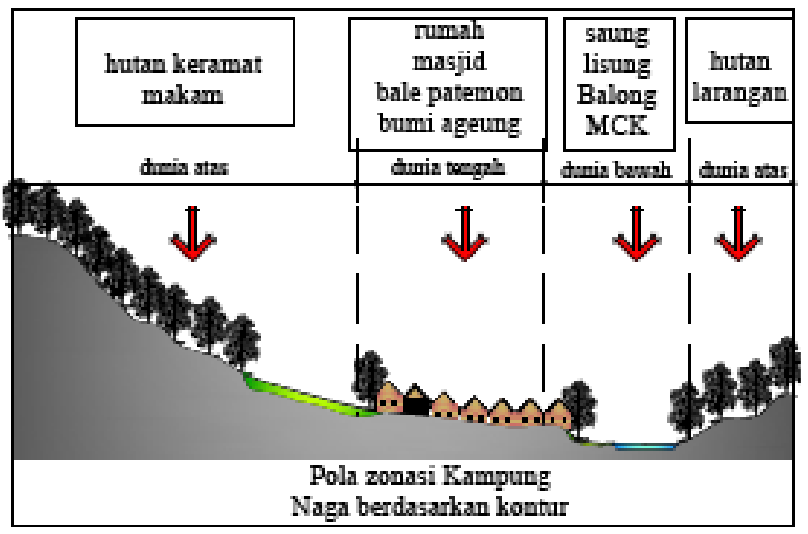

Gambar 4. Kosmologi Zonasi Kampung Naga berdasarkan kontur

Sumber : Analisis Pribadi, 2015

Orientasi Bangunan pada permukinan Kampung Naga sama yaitu menghadap ke utara dan selatan, dimana antar rumah bisa terjadi saling berhadapan atau saling membelakangi. Hal ini terkait dengan keadaan alam setempat, bahwa dengan arah yang sedemikian ini, air akan mudah turun dari atap ke tanah dan mengalir ke bagian yang lebih rendah. Ini merupakan salah satu bentuk adaptasi masyarakat terhadap kondisi alam sekitar, tidak melawan alam.

\section{Rumah dan Masjid}

Bentuk rumah pada Kampung Naga hampir sama, berbentuk panggung, dengan ketinggian $50 \mathrm{~cm}$ dari permukaan tanah, ini bertujuan agar terdapat sirkulasi dibawah dan sebagai pengontrol kelembaban udara dalam ruangan. Pembagian ruang rumah, secara vertikal terbagi menjadi 3 yaitu kolong, yang mewakili dunia bawah, palupuh atau lantai yang mewakili dunia tengah dan para atau langit-langit yang mewakili dunia atas.Pembagian ruang secara horisontal bisa dilihat pada tabel pada gambar 5 . Pembagian zonasi rumah cukup sederhana, hanya dibagi dalam 3 bagian, dengan fungsi dan peruntukan masing-masing yang sudah diatur sesuai hirarki ruang. Bagian depan adalah zona semi public, bagian tengah adalah ruang privat dan bagian belakang adalah ruang service. 
Dimensi rumah dan bangunan penunjang menggunakan skala visual penghuni

Pembagian ruang secara horisontal bisa dilihat pada tabel pada gambar 5. Pembagian zonasi rumah cukup sederhana, hanya dibagi dalam 3 bagian, dengan fungsi dan peruntukan masing-masing yang sudah diatur sesuai hirarki

Sedangkan material yang digunakan pada rumah di Kampung Naga diambil dari alam sekitar. Pemetaan materialnya bisa dilihat pada gambar 6. Upaya melokalisir pengambilan material diharapkan bisa menjadi strategi

\begin{tabular}{|c|l|l|l|}
\hline Posisi & \multicolumn{1}{|c|}{ Nama } & \multicolumn{1}{|c|}{ Untuk } & \multicolumn{1}{|c|}{ Fungsi } \\
\hline Depan & Tepas & Laki-laki & $\begin{array}{l}\text { Menerima tamu, tempat bekeja laki- } \\
\text { laki, tempat tidur tamu }\end{array}$ \\
\hline Tengah & T. Imah & Senva & $\begin{array}{l}\text { Berkumpul keluarga, tempat tidur } \\
\text { anak-anak }\end{array}$ \\
\hline & Pangkeng & Kelvarga & Tempat tidur su ami istri \\
\hline Belakang & Pawon & Wanita & $\begin{array}{l}\text { Tempak mas ak dan altivitas } \\
\text { perempuan }\end{array}$ \\
\hline & Goah & Wanita & Lumbung padi \\
\hline
\end{tabular}

Gambar 5. Pembagian ruang secara horisontal (sumber : analisa pribadi, 2015)

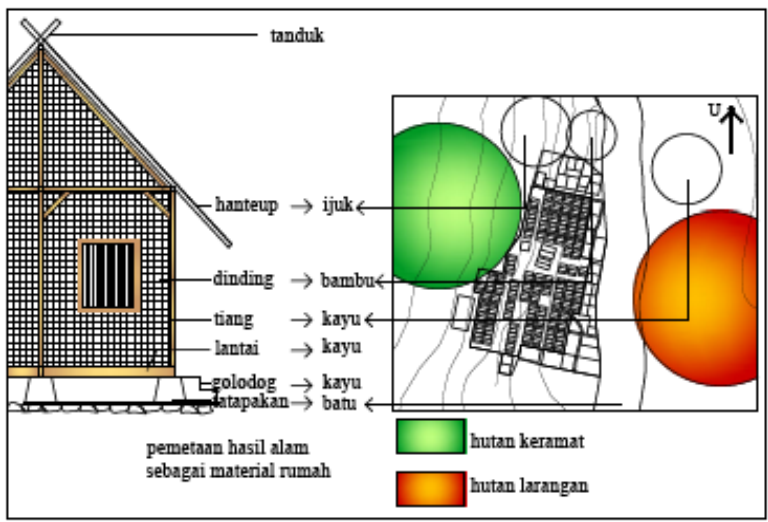

Gambar 6. Pemetaan hasil alam sebagai material bangunan

(sumber : Analisis Pribadi, 2015)

penjagaan iklim pada wilayah setempat. Gambar detail rumah sesuai hasil observasi terdapat pada gambar 7.

Bentuk bangunan baik rumah dan bangunan penunjang seperti masjid dan bale patemon (ruang pertemuan), berupa panggung diatas umpak semen. Lantai, struktur kolom, daun pintu dan jendela dari kayu dan dinding dari bambu, serta atap dari ijuk. Semua material diambil dari lingkungan setempat, dengan prinsip pengambilan secukupnya saja, tidak berlebihan dan ini merupakan upaya melestarikan keragaman hayati setempat. Pengambilan material alam secukupnya, diharapkan tidak ruang. Bagian depan adalah zona semi public, bagian tengah adalah ruang privat dan bagian belakang adalah ruang service. Dimensi rumah dan bangunan penunjang menggunakan skala visual penghuni.

merusak alam setempat dan sebagai upaya agar populasi tumbuhan tidak habis secara drastis, memberikan kesempatan kepada alam untuk meregenerasi tumbuhan secara alamiah
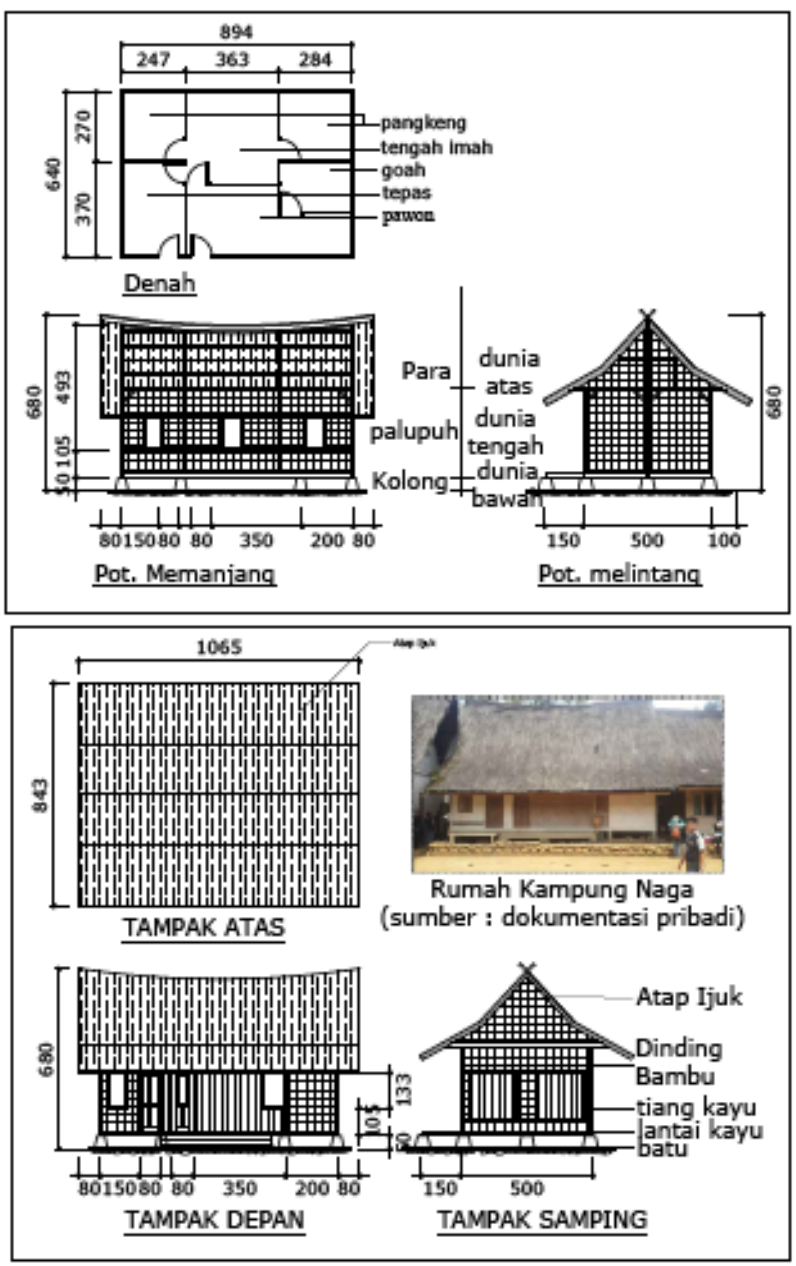

Gambar 7 Rumah Kampung Naga (sumber : analisa pribadi, 2015)

Manajemen penghawaan pada rumah dan bangunan penunjang lainnya menggunakan penghawaan alami. Sirkulasi penghawaan didapatkan dari bawah, melalui panggung bangunan dengan material lantai dari bambu yang tidak rapat. Pada bagian tengah sirkulasi penghawaan didapat dari bukaan jendela. Sedangkan pada bagian atap memanfaatkan atap ijik yang sangat fleksibel terhadap cuaca. 
Pencahayaan pada siang hari menggunakan pencahayaan alami, yaitu mengandalkan matahari melalui bukaan-bukaan seperti jendela. Sedangkan pada malam hari pencahayaan menggunakan lampu berbahan bakar minyak tanah, yang lebih ramah lingkungan. Tidak terdapatnya listrik pada perkampungan ini tentunya akan menekan biaya hidup masyarakat, disamping itu mampu mencegah masuknya produk-produk teknologi yang bisa mempengaruhi konsep awal permukiman kampung naga yang memang menolak teknologi.

Saung lisung

Adalah tempat menumbuk padi yang berlokasi di kawasan luar Kampung Naga sehingga terpisah dari rumah warga (kawasan permukiman). Letaknya diatas Balong (kolam Ikan), dengan tujuan agar sisa-sisa kotoran hasil tumbukan padi berupa uut (dedak) dan beunyeir (potongan kecil padi) bisa langsung dibuang dan dijadikan makanan ikan di kolam dibawahnya. Pemanfaatan uut dan beunyeir ini merupakan salah satu upaya masyarakat setempat dalam memanagemen limbah (re-use material).

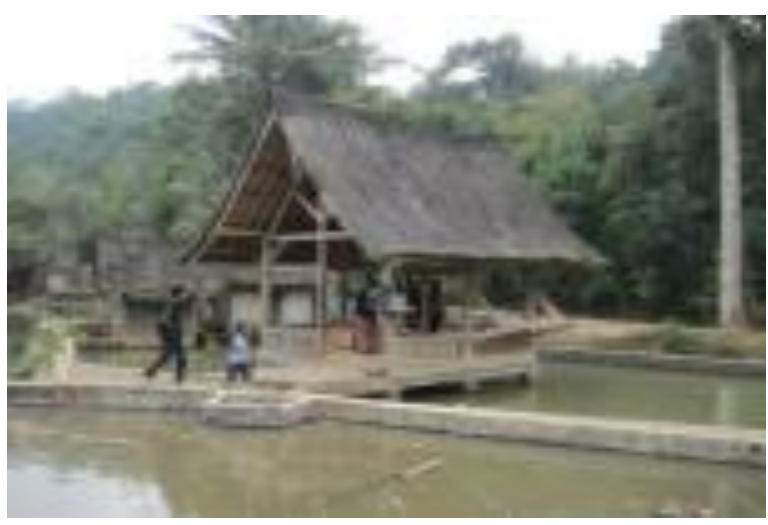

Gambar 8. Saung Lesung Kampung Naga

(sumber : analisa pribadi, 2015)
Pancuran, pacilingan atau tampian

Adalah area untuk mandi, cuci dan kakus. Bangunannya terletak di kawasan luar, diatas balong. Sumber air untuk keperluan mandi, MCK, wudhu, berasal dari sungai Ciwulan dan air permukaan yang melewati sawah masuk ke bak - bak penyaringan untuk dialirkan ke bak air wudhu dan jamban.

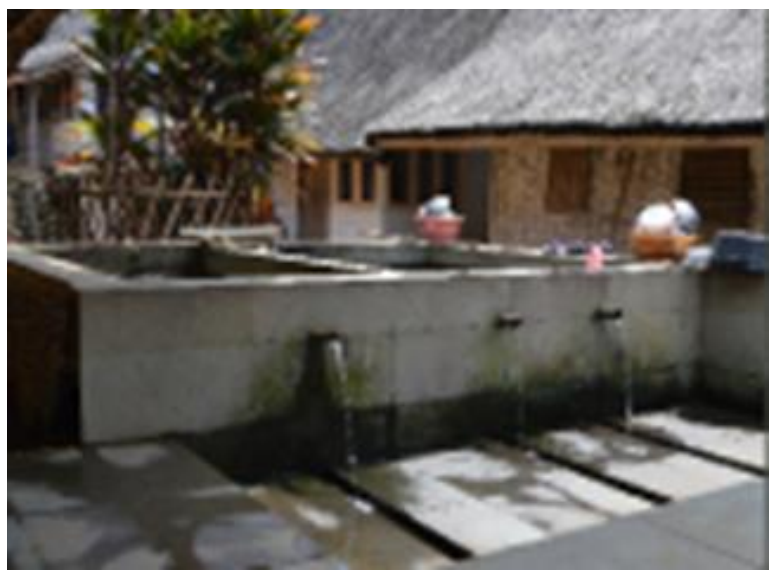

Gambar 9. Pancuran Kampung Naga (sumber : analisa pribadi, 2015)

Pengelolaan air bersih berasal dari mata air di sebelah Selatan kampung yang digunakan hanya untuk minum dan memasak, dan dialirkan melalui pipa-pipa dari bambu. Sedangkan air kotor dan limbah padat langsung dibuang dalam balong yang dibawahnya dipelihara ikan-ikan sebagai pengurai limbah.

Terkait dengan sustainable architectural, dibawah ini adalah analisa karya arsitektural Kampung Naga terhadap konsep Sustainable architecture menurut Paola Sassi

\begin{tabular}{|c|c|c|c|c|c|c|}
\hline \multirow[t]{2}{*}{ NO } & \multirow[t]{2}{*}{ ITEM } & \multirow{2}{*}{ DESCRIPTION } & \multicolumn{2}{|c|}{$\begin{array}{c}\text { SUSTAINABLE } \\
\text { ARCHITECTURE }\end{array}$} & \multicolumn{2}{|c|}{$\begin{array}{l}\text { LOCAL } \\
\text { GEBIUS }\end{array}$} \\
\hline & & & $\mathbf{T}$ & TT & $\mathbf{H}$ & TH \\
\hline \multirow[t]{2}{*}{1} & \multirow{2}{*}{ Natural Landscaping } & - sesuai tipologi tanah & $\mathrm{V}$ & & $\mathrm{V}$ & \\
\hline & & - management sumber air & $\mathrm{V}$ & & $\mathrm{V}$ & \\
\hline \multirow[t]{4}{*}{2} & \multirow{4}{*}{ Site Preservation } & - pelestarian keragaman hayati & $\mathrm{V}$ & & $\mathrm{V}$ & \\
\hline & & - pengelolaan air limbah & & $\mathrm{V}$ & & $\mathrm{V}$ \\
\hline & & - strategi penjagaan iklim & $\mathrm{V}$ & & $\mathrm{V}$ & \\
\hline & & - penanaman tumbuhan baru & $\mathrm{V}$ & & $\mathrm{V}$ & \\
\hline \multirow[t]{2}{*}{3} & \multirow[t]{2}{*}{ Visual Amenity } & - pengaturan zonasi & $\mathrm{V}$ & & $\mathrm{V}$ & \\
\hline & & - orientasi bangunan & & $\mathrm{V}$ & $\mathrm{V}$ & \\
\hline
\end{tabular}




\begin{tabular}{|c|c|c|c|c|c|c|}
\hline \multirow{2}{*}{ NO } & \multirow{2}{*}{ ITEM } & \multirow{2}{*}{ DESCRIPTION } & \multicolumn{2}{|c|}{$\begin{array}{c}\text { SUSTAINABLE } \\
\text { ARCHITECTURE }\end{array}$} & \multicolumn{2}{|c|}{$\begin{array}{l}\text { LOCAL } \\
\text { GEBIUS }\end{array}$} \\
\hline & & & $\mathbf{T}$ & TT & $\mathbf{H}$ & TH \\
\hline & & - skala sesuai visual penghuni & V & & $\mathrm{V}$ & \\
\hline \multirow[t]{2}{*}{4} & \multirow{2}{*}{$\begin{array}{l}\text { Economic and Social Well- } \\
\text { being }\end{array}$} & - economally profitable & & $\mathrm{V}$ & & $\mathrm{V}$ \\
\hline & & - socially acceptable & $\mathrm{V}$ & & $\mathrm{V}$ & \\
\hline \multirow[t]{2}{*}{5} & \multirow{2}{*}{$\begin{array}{l}\text { Daylighting and Natural } \\
\text { Ventilation }\end{array}$} & - pencahyaan alami & $\mathrm{V}$ & & $\mathrm{V}$ & \\
\hline & & - penghawaan alami & $\mathrm{V}$ & & $\mathrm{V}$ & \\
\hline \multirow[t]{3}{*}{6} & \multirow{3}{*}{ Water Management } & - pemanfaatan air bersih & $\mathrm{V}$ & & $\mathrm{V}$ & \\
\hline & & - pengolahan air kotor & $\mathrm{V}$ & & & $\mathrm{V}$ \\
\hline & & - pengolahan limbah padat & $\mathrm{V}$ & & & $\mathrm{V}$ \\
\hline \multirow[t]{4}{*}{7} & \multirow{4}{*}{$\begin{array}{l}\text { Reduce, Reuse, Recycle \& } \\
\text { Renewable Material }\end{array}$} & - reduce material & $\mathrm{V}$ & & $\mathrm{V}$ & \\
\hline & & - reuse material & $\mathrm{V}$ & & & $\mathrm{V}$ \\
\hline & & - recycle material & & $\mathrm{V}$ & & $\mathrm{V}$ \\
\hline & & - renewable material & $\mathrm{V}$ & & $\mathrm{V}$ & \\
\hline \multirow[t]{3}{*}{8} & \multirow{3}{*}{$\begin{array}{l}\text { Embodied Energy and } \\
\text { Energy Efficiency }\end{array}$} & - low technology & $\mathrm{V}$ & & $\mathrm{V}$ & \\
\hline & & - time efficiency & & $\mathrm{V}$ & $\mathrm{V}$ & \\
\hline & & - low cost & $\mathrm{V}$ & & $\mathrm{V}$ & \\
\hline
\end{tabular}

\section{KESIMPULAN}

Dari data dan analisa mengenai local genius dan sustainable architecture pada perkampungan diatas maka dapat diambil kesimpulan sebagai berikut :

- Kampung Naga menerapkan 78 \% konsep sustainable architecture berdasarkan teori Paolo Sassi.

- Local genius pada Kampung Naga yang berkaitan dengan konsep sustainable architecture adalah sebesar $74 \%$.

- Secara garis besar konsep local genius yang digunakan pada Kampung Naga selaras dengan konsep sustainable architecture.

- Hidup selaras dengan alam adalah cara bertahan masyarakat Kampung Naga terhadap permasalahan yang ada.

- Kesederhanaan, kebersamaan dan menghormati leluhur sebagai local genius masyarakat Kampung Naga, dijadikan sebagai dasar dan landasan dalam bermasyarakat, baik dalam hubungan antar manusia, manusia dengan alam, maupun manusia dengan Sang Penciptanya.

- Local genius yang mendasari terwujudnya karya arsitektural, pola ruang, zonasi, sirkulasi, pemilihan material bangunan dan aksessibilitas rumah dan bangunan penunjang pada Kampung Naga merupakan bagian dari konsep sustainable architecture, berdasarkan pengalaman nenek moyang yang dipelihara secara turun temurun dan mampu bertahan sampai dengan sekarang, yang mencerminkan tingkat intelektualitas arsitekturnya dalam kesederhanaan namun penuh filosofi mendalam.

Saran :

- Melestarikanlocal genius pada Kampung Naga, bukan hanya tanggungjawab pemerintah, namun masyarakat luas, khususnya masyarakat Kampung Naga itu sendiri, perlu upaya nyata untuk bisa mempertahankan kelocal-geniusan dan sustainable arschitecture concepts.

- Perlu upaya pemerintah dalam meningkatkan tingkat kecerdasan masyarakat Kampung Naga baik melalui pendidikan formal maupun non formal tanpa mengubah susunan dan mekanisme yang sudah berjalan karena pendidikan merupakan hak setiap warga negara Indonesia 


\section{DAFTAR PUSTAKA}

Dewi, P.F.R., Antariksa \& Surjono. 2008. Pelestarian Pola Perumahan Taneyan Lanjhang Pada Permukiman Di Desa Lombang Kabupaten Sumenep. Arsitektur e-journal.1

John M. Echols dan Hassan Syadily. 1998. Kamus Inggris Indonesia Gramedia Pustakan Utama.

Kepribadian Budaya Bangsa (Local Genius), 1986. Ayatrohaedi, Pustaka Jaya.

Machmud, 2006. Pola Permukiman Masyarakat Tradisional Ammatoa Kajang di Sulawesi Selatan. Jurnal Teknik. XIII (3):178-186

Moleong, Lexy J. 1998. Metode Penelitian Kualitatif. Cetakan ke-9. Bandung : Rosda Karya.

Sassi, Paola. 2006, Strategies for Sustainable Architecture, New York: Tailor \& Francis 